\title{
High and Low Toxin Production by a Non-toxigenic Strain of Clostridium botulinum Type C Following Infection with Type $\mathrm{C}$ Phages of Different Passage History
}

\author{
By K. OGUMA AND H. IIDA \\ Department of Bacteriology, School of Medicine, Hokkaido University, \\ Sapporo, Japan
}

(Received 20 November 1978; revised 25 January 1979)

Toxin production in Clostridium botulinum types $\mathrm{C}$ and $\mathrm{D}$ is governed by specific bacteriophages. Prior passages of a phage controlling type $C$ toxin production caused subsequently lysogenized bacteria to become variably toxigenic. This appears to be one of the causes of the decrease in toxigenicity which is common in some type $\mathrm{C}$ and $\mathrm{D}$ strains. The morphology of bacteria was also changed from rod-shaped to filamentous by infection with a successively propagated phage.

\section{INTRODUCTION}

The ability to synthesize toxin by Clostridium botulinum type $\mathrm{C}$ is transmitted from toxigenic to non-toxigenic strains by bacteriophages (Inoue \& Iida, 1970; Eklund et al., 1971); non-toxigenic strains become toxigenic by lysogenization or pseudolysogenization with phages (Eklund et al., 1971; Oguma, 1976). Hariharan \& Mitchell (1976) have reported that one non-toxigenic strain was converted to produce high or low levels of toxin when infected with different type $\mathrm{C}$ phages. They concluded that a non-toxigenic strain was converted to a low toxin producer by infection with a phage, c-st, obtained from a toxigenic type C strain, Stockholm. Phage c-st has, however, been in use in our laboratory as a means of converting non-toxigenic strains to high toxin producers. We now report that the titre of toxin produced by non-toxigenic organisms infected with type $\mathrm{C}$ phages varies according to the passage history of the phage employed. Morphological changes following (pseudo)lysogenization are also described.

\section{METHODS}

Phages. Phage c-st (Oguma et al., 1976a) was stored at $-80^{\circ} \mathrm{C}$ and at $4{ }^{\circ} \mathrm{C}$. The phage stored at $4{ }^{\circ} \mathrm{C}$ was mixed with an indicator strain of C. botulinum type C, (C)-AO2 (Inoue \& Iida, 1970), at intervals of about 2 weeks to maintain its titre. The original phage (stored at $-80^{\circ} \mathrm{C}$ ) and the passaged phages were purified by single plaque isolation (Oguma et al., 1976 b) and designated c-st and c-st', respectively. The original c-st phage converted $C$. botulinum (C)-AO2 to produce approximately $10^{4} \mathrm{LD}_{50}$ toxin $\mathrm{ml}^{-1}$ and c-st' phage converted the bacteria to produce $10^{1} \mathrm{LD}_{50}$ toxin $\mathrm{ml}^{-1}$. It was presumed that the converting ability of the phage had been changed by passaging through the indicator strain. Phage $c$-st was successively propagated through the indicator strain as follows. Phage lysate $(2 \mathrm{ml})$ was mixed with $15 \mathrm{ml}$ of an exponential phase culture of $C$. botulinum (C)-AO2 and incubated at $37^{\circ} \mathrm{C}$ for 3 to $4 \mathrm{~h}$ until visible lysis occurred. The lysate was stored at $4{ }^{\circ} \mathrm{C}$ for 1 to $3 \mathrm{~d}$ and the supernatant was then mixed with a culture in exponential phase. This procedure was repeated 40 times. The final lysate was filtered through a membrane filter (average pore size $450 \mathrm{~nm}$ ) and this phage preparation was designated c-st".

Phage-conversion to toxigenicity. Conversion to toxigenicity was studied in broth culture (conversion test) and on solid medium (plaque test). All converted cultures were grown at $37^{\circ} \mathrm{C}$ in $\mathrm{LYG}$ medium pH $7 \cdot 2$, containing $(\%, \mathrm{w} / \mathrm{v})$ : lactalbumin 1 ; yeast extract, 2 ; glucose, $0 \cdot 5$; cysteine. $\mathrm{HCl}, 0 \cdot 15$. For the conversion test, $2.5 \mathrm{ml}$ of a C. botulinum (C)-AO2 culture in exponential phase were mixed with $0.5 \mathrm{ml}$ of a phage suspension to give a multiplicity of infection of $0 \cdot 1$. After incubation at $37^{\circ} \mathrm{C}$ for $4 \mathrm{~h}, 0.2 \mathrm{ml}$ of the mixture 
Table 1. Toxicity in culture supernatants of Clostridium botulinum (C)-AO2 isolated in conversion and plaque tests for toxigenicity

Cultures of $C$. botulinum (C)-AO2 were prepared from 10 colonies and 10 plaques after infection with phage as described in Methods, and their toxin titres were determined.

Number of cultures of given toxin titre

\begin{tabular}{|c|c|c|c|c|c|c|}
\hline \multirow[b]{2}{*}{$\begin{array}{l}\text { Toxin titre } \\
\left(\text { MLD } \mathrm{ml}^{-1} \text { ) }\right.\end{array}$} & \multicolumn{2}{|c|}{ Infection with c-st } & \multicolumn{2}{|c|}{ Infection with c-st' } & \multicolumn{2}{|c|}{ Infection with c-st" } \\
\hline & $\begin{array}{c}\text { Conversion } \\
\text { test }\end{array}$ & $\begin{array}{c}\text { Plaque } \\
\text { test }\end{array}$ & $\begin{array}{c}\text { Conversion } \\
\text { test }\end{array}$ & $\begin{array}{l}\text { Plaque } \\
\text { test }\end{array}$ & $\begin{array}{c}\text { Conversion } \\
\text { test }\end{array}$ & $\begin{array}{l}\text { Plaque } \\
\text { test }\end{array}$ \\
\hline$<2$ & 1 & 0 & 2 & $3^{*}$ & $4\left(2,2^{*}\right)$ & $1^{*}$ \\
\hline 2 & 0 & 0 & 3 & 5 & 1 & 2 \\
\hline $2 \times 10^{1}$ & 0 & 0 & 5 & 2 & 5 & 6 \\
\hline $2 \times 10^{2}$ & 0 & 0 & 0 & 0 & 0 & 1 \\
\hline $2 \times 10^{3}$ & 2 & 2 & 0 & 0 & 0 & 0 \\
\hline $2 \times 10^{4}$ & 7 & 8 & 0 & 0 & 0 & 0 \\
\hline
\end{tabular}

* Mice suffered malaise but did not die.

was transferred to LYG medium $(15 \mathrm{ml})$, incubated for $7 \mathrm{~d}$ at $37^{\circ} \mathrm{C}$, and then the toxicity of the supernatant was determined in mice (see below). The conversion rate was determined as follows. After $4 \mathrm{~h}$ of contact be tween phage and bacteria, the mixture was centrifuged $(1000 \mathrm{~g}, 10 \mathrm{~min})$, and the pellet was streaked on blood-agar plates and incubated anaerobically at $37^{\circ} \mathrm{C}$ for $2 \mathrm{~d}$. Ten colonies picked at random were incubated in LYG medium and their toxin production was determined. The number of toxigenic cultures per 10 colonies tested was taken to be the conversion rate. For the plaque test, bacteria were picked from plaques on the specific agar for plaque formation (Oguma et al., 1976 b) and transferred with a platinum needle to LYG medium, incubated and tested for their toxicity.

Determination of toxin and haemagglutinin titres. Toxicity was determined by intraperitoneal injection into mice. The supernatants of culture fluids were diluted in serial 10 -fold steps with $0.02 \mathrm{M}$-phosphate buffer, pH 6.0 , containing gelatin $(0.2 \%, \mathrm{w} / \mathrm{v})$ and $0.5 \mathrm{ml}$ of each dilution was injected into three or five mice to determine the minimal lethal dose (MLD) or $\mathrm{LD}_{50}$, respectively. The mice were observed for $6 \mathrm{~d}$ and the $\mathrm{LD}_{50} \mathrm{ml}^{-1}$ was calculated by the method of Reed \& Muench (1938).

The haemagglutinin titre was obtained by mixing and incubating at $37^{\circ} \mathrm{C}$ for $2 \mathrm{~h}$ equal volumes $(0 \cdot 25 \mathrm{ml})$ of human red blood cells $(1 \%, \mathrm{v} / \mathrm{v})$ and culture supernatants which had been diluted in serial twofold steps with physiological saline pH 7.0 (Oguma et al., 1976a).

Ultrasonic disintegration of bacteria. A filamentous strain was incubated in $200 \mathrm{ml} \mathrm{LYG} \mathrm{medium} \mathrm{at}$ $37{ }^{\circ} \mathrm{C}$ for $7 \mathrm{~d}$. Organisms collected by centrifugation $(4000 \mathrm{~g}, 20 \mathrm{~min}$ ) were suspended in $10 \mathrm{ml}$ physiological saline (pH 6.0) and the suspension was divided into two. In one part the bacteria were washed three times and then resuspended in $5 \mathrm{ml}$ saline. Samples $(2 \mathrm{ml})$ of the washed and unwashed cell suspensions and the culture supernatant were treated ultrasonically (Kubota Co., model 200-M, 200 W, 10 min) and then centrifuged at $6000 \mathrm{~g}$ for $20 \mathrm{~min}$. Toxicity in the supernatants was tested and compared with that before ultrasonic treatment.

\section{RESULTS AND DISCUSSION}

\section{Converting ability of phage}

The conversion test was done with three phages: $\mathrm{c}$-st, c-st' and c-st". Clostridium botulinum (C)-AO2 infected with c-st phage was converted to produce $3 \cdot 16 \times 10^{4} \mathrm{LD}_{50} \mathrm{ml}^{-1}$ (high toxin production), but with c-st' and c-st" phages it was converted to produce less than $10^{2} \mathrm{LD}_{50}$ $\mathrm{ml}^{-1}$ (low toxin production). The conversion rate of the three phages was similar (8/10 to $9 / 10$ ). However, the titres of toxin produced were different when each isolated colony or plaque was examined (Table 1). All 30 cultures prepared from plaques were toxigenic; toxin production resulting from infection with c-st phage was high, whilst that by cultures infected with c-st' or c-st" phages was low. Haemagglutinin activity in cultures also varied with toxigenicity. The haemagglutinin titre of highly toxigenic cultures was more than $64 \times$, but there was no haemagglutination by cultures with low toxigenicity. These results indicate that the converting ability of each phage becomes low after many propagations through the indicator strain and that the production of toxin and haemag- 



Fig. 1. Morphology of phage-infected cells: $(a)$ infected with c-st and c-st' phages (rods);

(b) infected with c-st" phage (filaments).

glutinin by bacteria infected with converting phages depends upon the passage history of the phages. This could be one of the causes of the decrease in toxigenicity common in some type C and D strains. Our observations differed from those of Hariharan \& Mitchell (1976), who reported that the conversion rate of highly toxigenic cultures was high $(100 \%)$ whereas that of cultures of low toxigenicity was only $20 \%$, and that the toxicity of each converted culture was similar (about $10^{4}$ mouse $\mathrm{LD}_{50} \mathrm{ml}^{-1}$ ). Variability in the converting rate of phage might be an alternative explanation for the low toxigenicity of converted cultures.

\section{Morphology of phage-infected bacteria}

The repeatedly propagated c-st" phage was more lytic than the other two phages in broth culture and gave larger plaques on solid medium. The organisms infected by c-st and c-st' phages showed homogeneous turbidity when grown in LYG medium, whilst bacteria infected with c-st" phage grew as a deposit at the bottom of the test tube. The number of bacteria at the peak of growth was similar in all these cultures. The former organisms were typical rods and the latter were filamentous (Fig. 1). Four filamentous cultures of low toxigenicity were subcultured successively 10 times in LYG medium to study the relationship between toxigenicity, morphology and the nature of (pre)prophage carriage. All four cultures became non-toxigenic after the transfers; three returned to rod forms but one remained filamentous. Cultures of filamentous and rod-shaped bacteria were plated on blood agar plates and 10 colonies of each were examined. The shapes of the two sets of colonies were similar, but colonies of the filamentous cells were more viscous than those of rod-shaped bacteria. All 20 colonies were non-toxigenic and their component bacteria showed the same morphology as that of the inoculum. These cultures were then separately mixed with c-st and c-st" phages and the conversion test was carried out. Rod-shaped cells were converted to highly toxigenic cultures by c-st phage but became only low toxin producers with c-st" phage. The low toxin producers grew as filaments. These results strongly suggest that the change in morphology from rods to filaments is closely related to (pseudo)lysogenization with c-st" phage. In support of this, filaments were insusceptible to both c-st and c-st" phages. It is possible that these phage-insusceptible bacteria had been lysogenized by a nonconverting mutant phage (Oguma, 1976). We presume that this morphological change is related to the virulence of phage and are studying the phenomenon further.

\section{Toxicity of filamentous culture after ultrasonic disintegration}

The low toxicity in the supernatants of filamentous bacteria could have been due to a difficulty in releasing toxin from the bacteria, and so toxicity was compared before and after ultrasonic disintegration of organisms (see Methods). There was little difference in toxicity in any of the preparations, indicating that the low toxigenicity of a culture of filamentous organisms is not due to a difficulty in releasing toxin but to a low level of toxin production. 


\section{REFERENCES}

Eklund, M. W., Poysky, F. T., Reed, S. M. \& Smith, C. A. (1971). Bacteriophages and toxigenicity of Clostridium botulinum type C. Science 172, 480-482.

Hariharan, H. \& Mitchell, W. R. (1976). Observations on bacteriophages of Clostridium botulinum type $\mathrm{C}$ isolated from different sources and the role of certain phages in toxigenicity. Applied and Environmental Microbiology 32, 145-158.

Inoue, K. \& IIDA, H. (1970). Conversion of toxigenicity in Clostridium botulinum type C. Japanese Journal of Microbiology 14, 87-89.

Oguma, K. (1976). The stability of toxigenicity in
Clostridium botulinum types C and D. Journal of General Microbiology 92, 67-75.

Oguma, K., Iida, H. \& Shiozaki, M. (1976a). Phage conversion to hemagglutinin production in Clostridium botulinum types $\mathrm{C}$ and D. Infection and Immunity 14, 597-602.

Oguma, K., Iida, H., Shiozaki, M. \& Inoue, K. $(1976 b)$. Antigenicity of converting phages obtained from Clostridium botulinum types C and D. Infection and Immunity 13, 855-860.

ReED, L. J. \& MuenCH, H. (1938). A simple method of estimating fifty per cent endpoints. American Journal of Hygiene 27, 493-497. 